\title{
Herpetofaunal Diversity in Nagarjun Forest
}

\author{
Ganesh K. Pokhrel', Prakash C. Aryal ${ }^{1}$, Karan B. Shah ${ }^{2}$, Bishal Rijal ${ }^{1}$, Madan K. Suwal ${ }^{1}$, \\ Subash C. Kharel ${ }^{1}$, Evanath Paudel ${ }^{1}$ and Man K. Dhamala ${ }^{1}$ \\ ${ }^{1}$ Companions for Amphibians and Reptiles of Nepal (CARON) Kathmandu \\ ${ }^{2}$ Natural History Museum, Soyambhu, Kathmandu \\ e-mail:ganeshkpokhrel@caron.org.np
}

\begin{abstract}
The composition of amphibians and reptiles diversity in the Nagarjun forest of Shivapuri Nagarjun National Park was studied. Purposive transect and opportunistic survey methods were adopted to estimate species diversity. The species caught during survey were identified on the spot using field guide and released in-situ. Transects were distributed across six distinct micro-watersheds in the forest. In total, 134 individuals belonging to 11 species were observed. The spatial distribution patterns of the species were also mapped. The condition and potential threat of the habitat is also assessed during this study.
\end{abstract}

Key words: amphibians, diversity, transect survey, reptiles

\section{Introduction}

Herpetofauna (amphibians and reptiles) are correspondingly defenseless against the global threats of deforestation, draining of wetlands, and pollution from agricultural runoff (Gibbons et al. 2000). Amphibian populations have suffered widespread declines and extinctions in recent decades (Kiesecker et al. 2001). Amphibians are frequently characterized as having limited dispersal abilities, strong site fidelity and spatially disjunctive breeding habitat (Smith \& Green 2005). Limited dispersal ability may further increase the vulnerability of amphibians and reptiles to changes in climate. Slight changes in water level in breeding ponds can trigger reproductive failure and, in a single year, cause a severe drop in the population size of short-lived species; persistent changes can lead to extinctions of species (Arau Jo et al. 2006). Although, the amphibian decline problem is a serious threat, reptiles appear to be in even greater danger of extinction worldwide (Gibbons et al. 2000). So, the assessments of amphibian and reptile diversity require exploration of previously unvisited areas, comprehensive surveys of poorly known areas, and revisiting of localities that have not been assessed in the last decade (Parra et al. 2007).

South Asia has a rich diversity of amphibian and reptilian fauna including several unique and endemic species (Shah \& Tiwari 2004). Ecological research efforts and suitable protection of species naturally depend on the knowledge of species occurrences in a particular area. This information in readily accessible form is lack-ing for several taxonomic groups and regions in Southeast Asia (Sodhi \& Brook 2006). It 
appears that only about $50 \%$ of the biodiversity of amphibians in South Asia has been discovered. However, there is increasing habitat loss and fragmentation, which are rapidly depleting amphibian populations. Very few species have been described from disturbed habitats, indicating a diminished species composition when compared with the original habitat (Molur 2008).

Fourteen species of herpetofauna are endemic to Nepal. A total of 17 herpetofaunal species are enlisted as threatened in Nepal, of which six species are globally threatened (Bhuju et al. 2007). As herpetofauna is one of the poorly studied faunal group in the country, their present status is also poorly known (CEPF 2005). A publication "Amphibians and Reptiles of Nepal" edited by Schleich and Catstle (2002) provides an account of 50 amphibians and 123 reptiles. The herpetofauna in Nepal is relatively richer compared to other South Asian countries well over 206 species and subspecies, including 59 amphibian species of which 15 are listed as globally threatened. Amphibians and reptiles of Nepal face severe threat of extinction. Nepal has a reduced species composition compared with the 2001 checklists (Molur 2008).
Biodiversity resource profile indicates the current checklists of Shivapuri National Park include 3 herpetofauna species. But, this is sought to be the gap in study of herpetofauna in the park. This gap has created a situation of 'No names, no conservation' for herpetofauna since no systematic exploration works are ongoing. The park has different habitat conditions owing to topographical and microclimatic variations. The study is carried out with the aim to generate the current status of herpetofauna in the area and to sensitize the conservation efforts. Further, it is expected to minimize the gap in herpetological studies in Nepal. This paper has revealed the status of amphibians and reptiles diversity of Nagarjuna forest at different habitat.

\section{Study area}

The study area, Nagarjun forest, is inside the Shivapuri Nagarjun National Park. The area covers $16 \mathrm{~km}^{2}$ in the western part of the national park. The study area extends from base of Nagarjun forest (around $1350 \mathrm{~m}$ a.s.l.) to top of Nagarjun hill (2100m a.s.l.). The study area is one of the important natural areas along the Kathmandu valley rim.

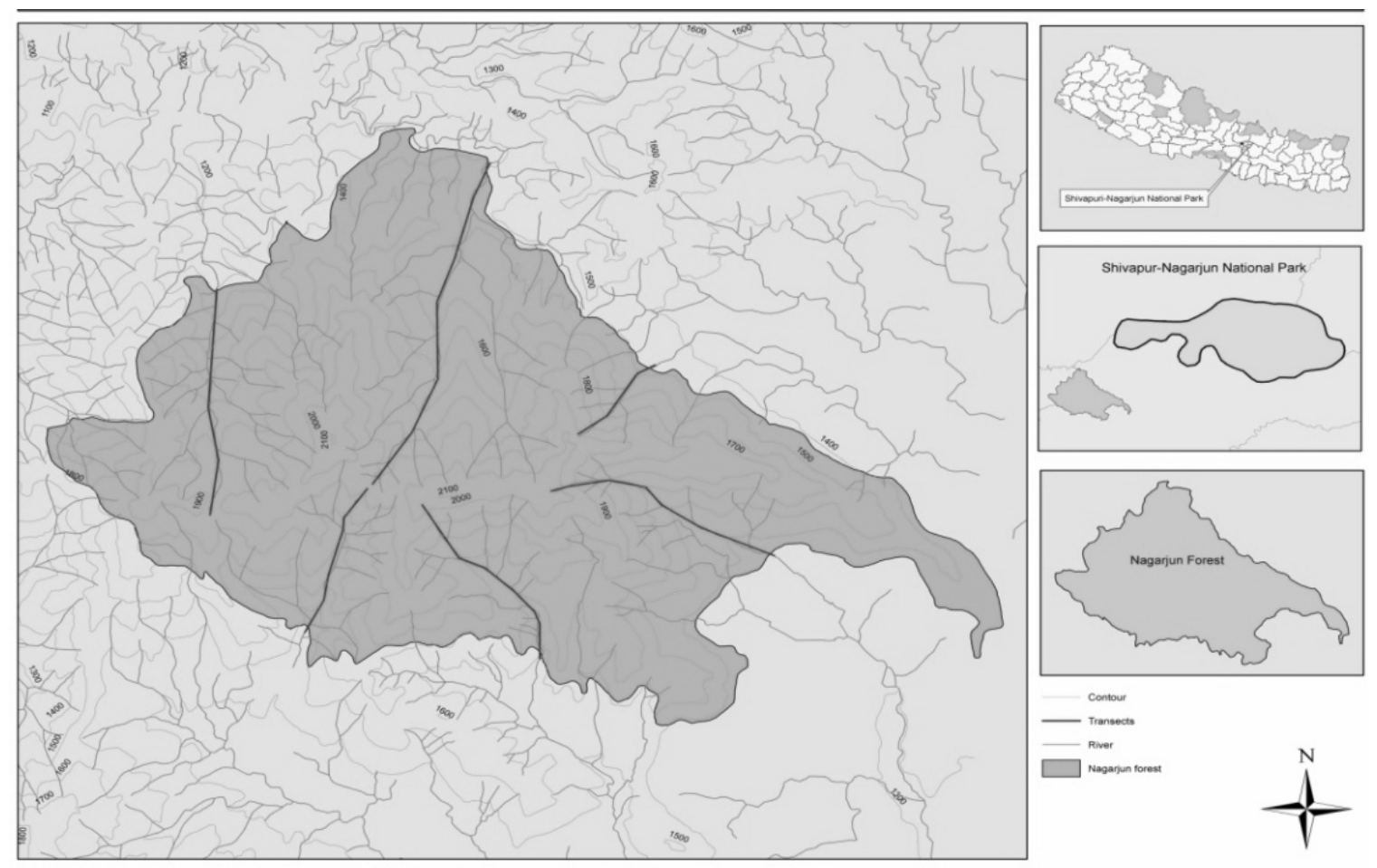

Fig.1. Depicts location of the study area 
Nagarjun forest area is a typical Mahabharat hill and bears mostly sub-tropical type of climate and partly temperate climate (Chaudhary 1998). The southern side is sunny and is evidently much drier than the northern forested side. The climatic data of the Nagarjun area is not available. According to the climatic data of nearest meteorological stations i.e. Dhunibesi and Kakani, average relative humidity of the area ranges from $54.7 \%$ (April) at Dhunibesi to 94.29\% (July) at Kakani. Similarly, the average monthly rainfall ranges from $5.15 \mathrm{~mm}$ (December) to 548.73mm (July).

\section{Methodology}

The field methods involved the approaches for the basic exploration of the herpetofauna in the Nagarjun forest area. Purposive transect method was adopted in order to sampling in the area for intensive study (Fig.2). Diurnal transect walks were carried to locate the amphibians and reptiles. Hand picking (using equipments for handling the reptiles and amphibians) method was used in all the sites. The species caught during survey were spot identified using field guide of Shah and Tiwari (2004) and released in-situ.
Opportunistic surveys were also carried out in other parts from sample transects based on Gardner and Fitzherbert (2007).

Field surveys were carried out during June-August, 2009 for 20 days covering 6 watersheds in Nagarjuna forest. In each transect (along the forest trails and streams) four persons walked covering the distance of $10 \mathrm{~m}$ on both sides. During walking along the transects, species were searched by overturning the logs, looking on the trunk and hollows of trees and rocks, overturning of stones along the water way, etc. Geographical position of species encounter location was recorded by GPS.

The nearby residents were contacted and information was obtained through interviews. The color photographs of the potential amphibians and reptiles were shown to people and asked to explain the features. Whenever more than one individual in more than two instances could explain the features, the species were noted and later consulted with the herpetologists to confirm the occurrences.

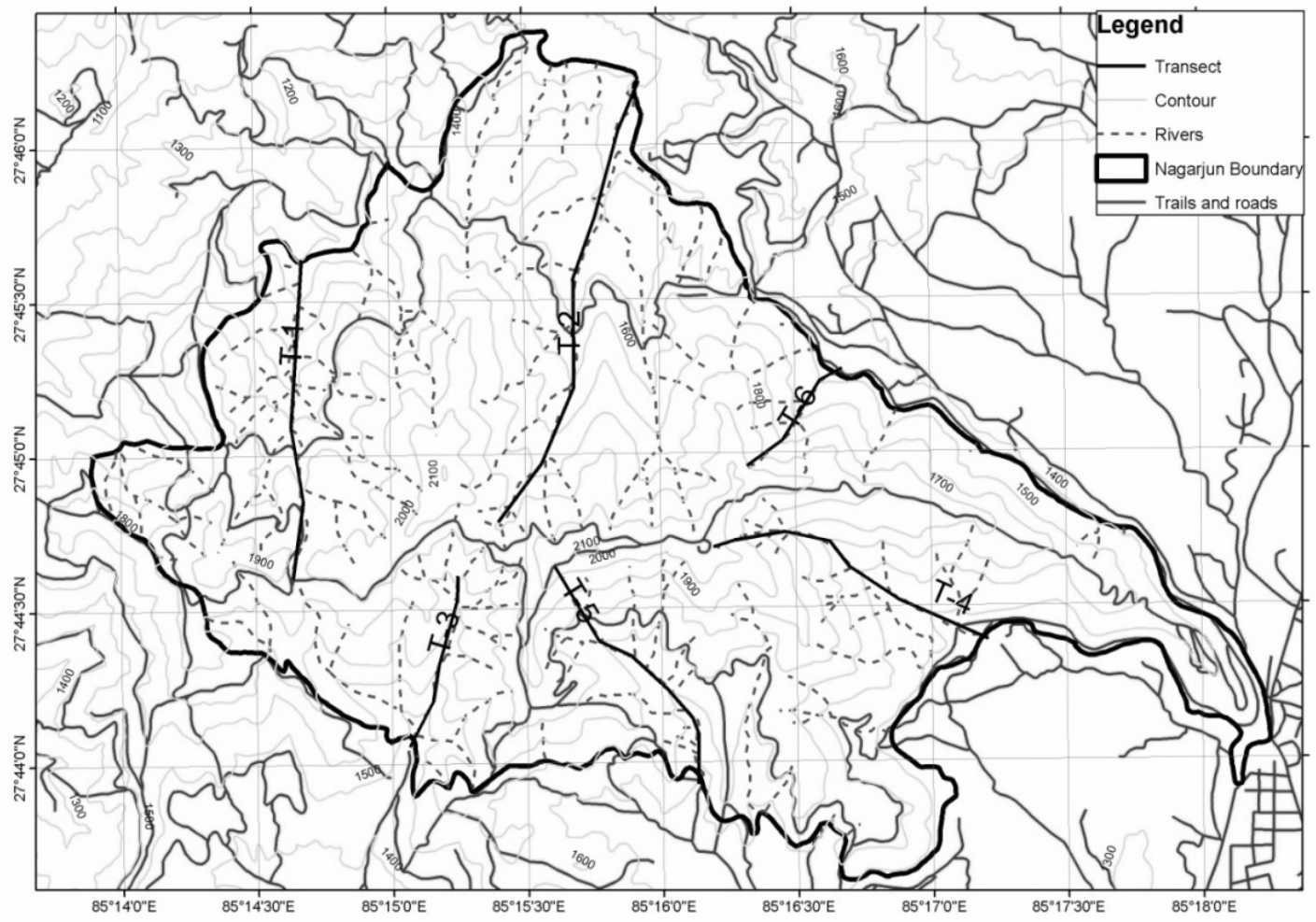

Fig.2. Map showing sampling transects 


\section{Results and Discussion Species diversity}

Altogether, 134 individuals belonging to 11 species of herpetofauna (three amphibians and eight reptiles) were recorded from the area. Naja kaouthia was encountered only once. The other species with less encounter $(<10)$ were Bufo melanostictus, Trachischium leave, Mabuya carinata, Amphiesma platyceps and Japalura variegate. Five species namely, Japalura variegate, Trachischium tenuiceps, Asymblepharus sikimmensis, Calotes versicolor versicolor, Megophrys parva and Limnonectes syhadrensis were observed commonly i.e. >10 individuals. Megophrys parva was the most commonly observed species among all (and amphibians) whereas Calotes versicolor versicolor was the most common among reptiles.

Table 1. Species encountered in Nagarjun during the forest survey (June-August)

\begin{tabular}{lllcc}
\hline SN & Species & Family & No. of Individuals & Abundance \\
\hline 1 & Naja kaouthia & Elapidae & 1 & $\mathrm{R}$ \\
2 & Bufo melanostictus & Bufonidae & 3 & $\mathrm{O}$ \\
3 & Trachischium leave & Colubridae & 3 & $\mathrm{O}$ \\
4 & Mabuya carinata & Scincidae & 5 & $\mathrm{C}$ \\
5 & Amphiesma platyceps & Colubridae & 7 & $\mathrm{C}$ \\
6 & Limnonectes syhadrensis & Ranidae & 13 & $\mathrm{C}$ \\
7 & Trachischium tenuiceps & Colubridae & 14 & $\mathrm{C}$ \\
8 & Asymblepharus sikimmensis & Scincidae & 22 & $\mathrm{C}$ \\
9 & Calotes versicolor versicolor & Agamidae & 24 & $\mathrm{C}$ \\
10 & Megophrys parva & Megophrydae & 35 & $\mathrm{C}$ \\
11 & Japalura variegata & Agamidae & 7 & $\mathrm{C}$ \\
\hline
\end{tabular}

Some of the species records were made through the local information. The following five species (1 amphibian and 4 reptiles) records were made through the secondary sources.

Table 2. Species information from secondary sources

\begin{tabular}{l|l|l|l}
\hline SN & Species & Common Name & Source \\
\hline 1 & Ophiophagus hannah & King cobra & NHM* \\
2 & Varanus bengalensis & Common monitor & Local Residents \\
3 & Paa leigibii & Liebig's Paa frog & Local Residents \\
4 & Trimeresurus albolabris & White lipped pit viper & Local Residents \\
5 & Ptyas mucosa mucosa & Asiatic rat snake & Local Residents \\
\hline
\end{tabular}




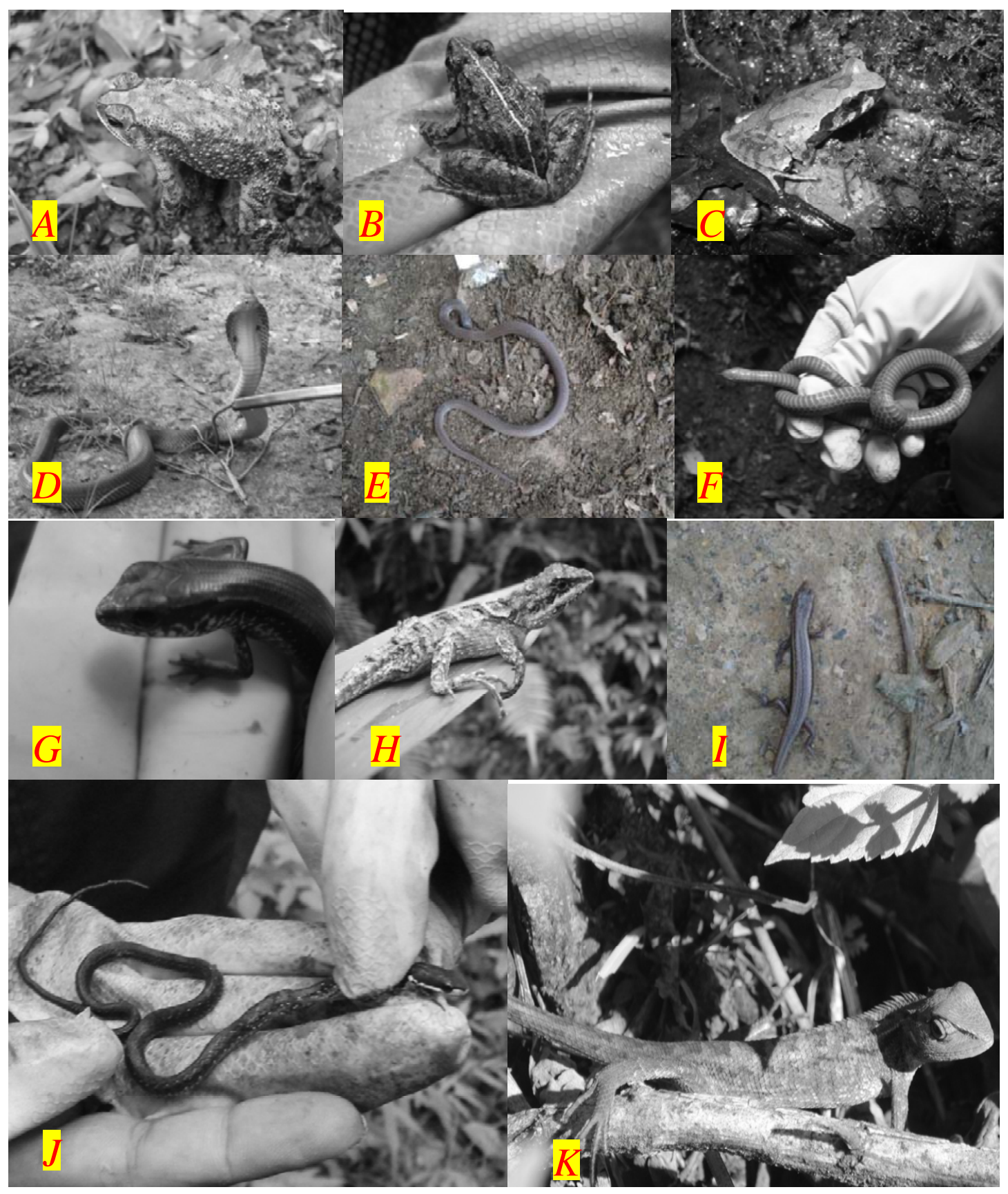

Fig. 3. Amphibians and reptiles encountered in the Nagarjun forest: (A) Bufo melanostictus;(B) Limnonectes syhadrensis;(C) Megophrys parva;(D) Naja kaouthia;(E) Trachischium leave;(F) Trachischium tenuiceps;(G) Asymblepharus sikimmensis;(H) Japalura variegate;(I) Mabuya carinata;(J) Amphiesma platyceps;(K) Calotes versicolor. 


\section{Distribution of Herpetofauna}

The habitat comprises of shrub area, slight to moderately dense forests along with some springs making a combination of aquatic habitats at places. The good forest growths and springs make diverse habitat conditions for herpetofauna in Nagarjun forest. The slope landscape, caves and varied microclimatic conditions harbour diverse
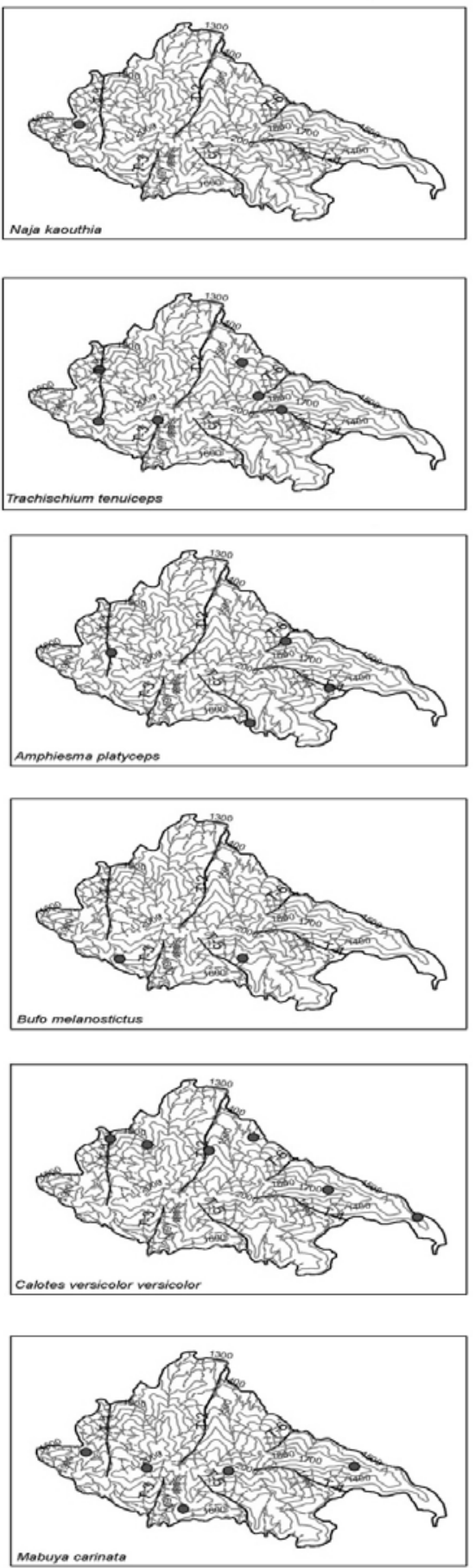

herpetofaunal species. Surveys were carried out in and around water bodies (streams). None of the species encountered during the entire field survey in the water bodies. Using the GPS points of the site observations, the distribution of herpetofauna was mapped (Fig.4) in Arc GIS 9.2.
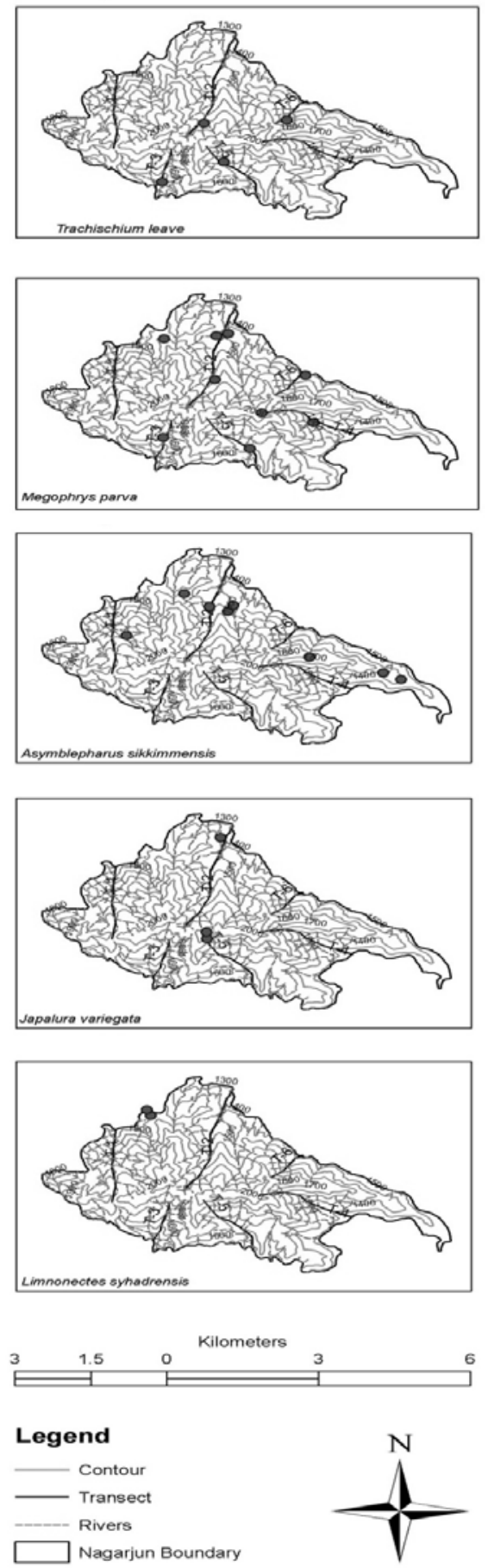

Fig.4. Species distribution map in Nagarjuna forest 
All the species of snakes (Elapidae and Colubridae) and frogs (Bufonidae, Megophrydae, Ranidae) observed during the survey were within a distance of $50 \mathrm{~m}$ from water bodies. On the other hand the species of Agamidae (Lizards) and Scincidae (Skinks) were encountered independent of the distance of water bodies.

\section{Conservation Issues}

Nagarjuna forest is away from grazing problems. However, other human activities were not uncommon. Road networks linking villages to Kathmandu were major disturbance factors. Accidental killings of herps along the road were observed. And annual clearings of road edges were also noticed. The forest is protected but clearings of forest floor by security (Nepal Army) also disturbed the habitat of herps. It was also observed that illegal entry of hikers/trekkers/picnickers inside the forest also disturbed the herpetofaunal species. Illegal fishing in the stream was also seen as a disturbance factors to the herptofauna. Local practices of fuel wood and fodder collection were frequent in the area; particularly near the settlements which also degrade the habitat.

\section{Acknowledgements}

We are most grateful to Nepal Academy of Science and Technology (NAST) for research grant to carry out the study in the area. Our sincere thank goes to the Department of National Parks and Wildlife Conservation (DNPWC) and Sivapuri Nagarjun National Park office and Nepal Army for giving permission to conduct the study in the area. We thank Mr. Bed Prasad Bhurtel, Mr. Laxman Phuyal, Mr. Yagya Bhatt, Mr. Resham Baniya and Mr. Roshan Rijal for their help during field work.

\section{References}

Arau Jo, M. B., W. Thuiller, and R. G. Pearson. 2006. Climate warming and the decline of amphibians and reptiles in Europe. Journal of Biogeography 33:17121728.
Bhuju, U. R., P. R. Shakya, T. B. Shrestha and S. Shrestha. 2007. Nepal biodiversity resource book: Protected areas, ramsar sites, and world heritage sites. International Center for Integrated Mountain Development (ICIMOD) and Ministry of Environment, Science and Technology-Government of Nepal (MoEST/GON).

CEPF. 2005. Ecosystem profile: Eastern Himalayas region. Critical Ecosystem Partnership Fund. Kathmandu, Nepal, 97 pp.

Chaudhary, R.P. 1998. Biodiversity in Nepal. Devi, S. and Tecpress Books, Soi WaWattansilp, Pratunam, Bangkok, Thailand, pp.23-30 and 174-239.

Gardner, T. A., and E. B. Fitzherbert. 2007. Spatial and temporal patterns of abundance and diversity of an East African leaf litter amphibian fauna. Biotropica 39:105-113.

Gibbons, J. W., D. E. Scott, T. J. Ryan, K. A. Buhlman, T. D. Tuberville, B. S. Metts, J. L. Greene, T. Mills, Y. Leiden, S. Poppy, and C. T. Winne. 2000. The global decline of reptiles, Déjà Vu amphibians. BioScience 50:653-666.

Kiesecker, J. M., A. R. Blaustein, and L. K. Belden. 2001. Complex causes of amphibian population declines. Nature 410:681-683.

Molur, S., 2008. South Asian amphibians: taxonomy, diversity and conservation status. International Zoo Yearbook 42:143-157.

Parra, G., R. Brown, J. Hanken, B. Hedges, R. Heyer, S. Kuzmin, E. Lavilla, S. Lötters, B. Pimenta, S. Richards, M. O. Rödel, R. O. de Sá, and D. Wake. 2007. Systematics and conservation. In: Amphibian Conservation Action Plan (Eds C. Gascon, J. P. Collins, R. D. Moore, D. R. Church, J. E. McKay, and J. R. Mendelson). IUCN/SSC Amphibian Specialist Group, Gland, Switzerland and Cambridge, UK, pp. 45-48.

Schleich, H. Herman and W. Kastle. 2002. Amphibians and reptiles of Nepal. A.R.G. Gantner Verlag K. G., Germany.

Shah, K. B., and S. Tiwari. 2004. Herpetofauna of Nepal: A Conservation Companion. IUCN- Nepal, Kathmandu Nepal, Viii+237 pp.

Smith, M. A., and D. M. Green. 2005. Dispersal and the metapopulation paradigm in amphibian ecology and conservation: Are all amphibian populations metapopulations? ecography 28:110-128.

Sodhi, N. S. and B. W. Brook. 2006. Southeast Asian biodiversity in crisis. Cambridge. Cambridge University Press. 
Nepal Journal of Science and Technology 12 (2011) 358-365 